\title{
FEASIBILITY OF A BRAYTON CYCLE AUTOMOTIVE AIR CONDITIONING SYSTEM
}

\author{
L. H. M. Beatrice ${ }^{\mathrm{a}}$, \\ and F. A. S. Fiorelli ${ }^{\mathrm{a}}$ \\ ${ }^{a}$ Universidade de São Paulo \\ Escola Politécnica \\ Departamento de Engenharia Mecânica \\ Av. Prof. Mello Moraes, 2231 \\ ABSTRACT \\ The goal of this work is to develop a preliminary analysis on the feasibility \\ of using an alternative automotive air conditioning system based on the \\ Brayton cycle, to be assembled using a turbocompression-intercooling \\ system configuration available in the market. The first step of the analysis \\ was a thermodynamic study to define the system capacity and parameters \\ for selecting the system components. The next step was to select from \\ turbocompressor maps a suitable model for the application, and to \\ determine pressures/temperatures throughout the system in order to evaluate \\ intercooler capacity and select a suitable model available in the market. The \\ impact of the turbocompression system was also analyzed in engine \\ performance. The proposed turbocompression system requires $1,7 \mathrm{~kW}$ from \\ the engine, which is very similar to a conventional air conditioning system \\ requirement. In terms of weight, this preliminary analysis indicated that the \\ proposed system is about $1,0 \mathrm{~kg}$ heavier than the conventional system. The \\ analysis indicated that the alternative system is about $56 \%$ more expensive \\ than the conventional one, but on the other hand presents a $24 \%$ lower \\ maintenance cost . Considering the results of the preliminary analysis, the \\ proposed system is technically feasible for application in automotive air \\ conditioning, but requires a design optimization process in order to reduce \\ its weight and initial costs, which might allow lower maintenance costs to \\ payback the alternative system. \\ Keywords: Automotive Air Conditioning, Brayton Cycle, \\ Thermoeconomical Analysis.
}

\section{NOMENCLATURE}

COP coefficient of performance

$c_{p} \quad$ specific heat at constant pressure

h specific enthalpy

$\mathrm{k} \quad$ isentropic coefficient

m mass flow rate

$\mathrm{p}$ pressure

Q heat transfer

$T$ temperature

$\dot{\mathrm{W}}$ power

\section{Greek symbols}

$\phi \quad$ relative humidity

$\eta \quad$ efficiency

$\omega \quad$ absolute humidity

\section{Subscripts}

$0 \quad$ external

a air

C compressor

E evaporator outlet

$\mathrm{H}$ warm region

in inlet

L cold region

net net

out outlet

$\mathrm{s} \quad$ isentropic

w water

\section{INTRODUCTION}

The automotive air conditioning systems in use are based on the vapor compression refrigeration cycle, and the required power to the system is provided to the compressor by the vehicle engine through a magnetic clutch. Such power supply to compressor has a significant impact on engine fuel consumption and power transfer to tires, particularly for economic class cars. According to Kaynakli \& Horuz (2003), a typical automotive air conditioning system requires a compressor power of about 1,6-1,7 $\mathrm{kW}$ from the engine.

Nowadays there is a global scenario of instability in the petrol market, with a price increase tendency in the medium/long term, as well as environmental concerns about pollution and global warming. Internal combustion engine-driven vehicles are an important source of pollution, and the optimization of peripheral systems connected to the engine, such as the air conditioning system, is important and required to reduce vehicle fuel consumption and pollutant emissions. Another environmental aspect that affects air conditioning systems is that the halogenated refrigerant typically used in the system contributes to global warming, and the development of a system that eliminates such substances is also important. 
Considering these aspects, the goal of this work is to develop a preliminary technical-economical analysis on the viability of using an alternative turbocompression automotive air conditioning system based on the Brayton cycle, to be assembled using a turbocompression-intercooling system configuration available in the market, as shown in Fig. 1. This kind of system is already in use in aircrafts and it is interesting in environmental terms since it uses air as working fluid, thus eliminating the impact of halogenated refrigerants in global warming. This configuration may also optimize fuel usage since it retrieves energy from combustion gases to power AC system.

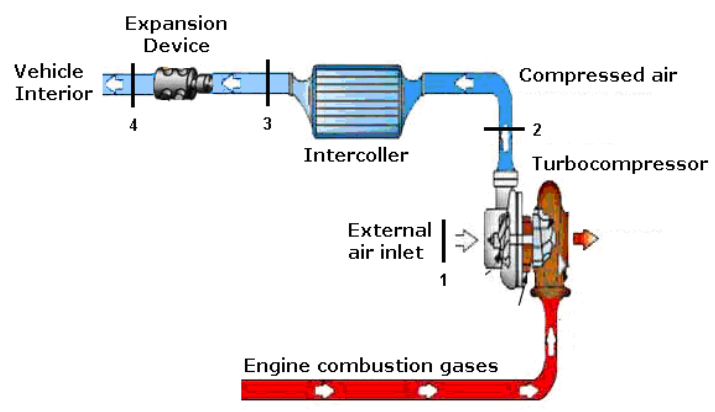

Figure 1. Turbocompression automotive air conditioning system.

\section{REFRIGERATION CYCLES}

As stated before, nowadays automotive air conditioning systems are based on the vapor compression refrigeration cycle (Fig. 2). Heat and work transfers in the cycle are given by Eq. (1) considering steady state and negligible potential and kinetic energy variations:

$\dot{\mathrm{Q}}-\dot{\mathrm{W}}=\dot{\mathrm{m}}\left(\mathrm{h}_{\text {out }}-\mathrm{h}_{\text {in }}\right)$

Cycle performance can be evaluated by coefficient of performance COP, given by:

$\mathrm{COP}=\left|\frac{\dot{\mathrm{Q}}_{\mathrm{L}}}{\dot{\mathrm{W}}_{\mathrm{C}}}\right|=\frac{\mathrm{h}_{1}-\mathrm{h}_{4}}{\mathrm{~h}_{2}-\mathrm{h}_{1}}$

The reverse Brayton closed refrigeration cycle (Fig. 3) is the theoretical cycle that approaches the proposed turbocompression AC system presented in Fig. 1. In this cycle, isothermal heat exchanges are replaced by isobaric ones, as shown in the T-s diagram of Fig. 3. Considering reversible processes, $\mathrm{COP}$ for such cycle is given by:

$\mathrm{COP}=\left|\frac{\dot{\mathrm{Q}}_{4-1}}{\dot{\mathrm{W}}_{\text {net }}}\right|=\frac{\mathrm{T}_{1}-\mathrm{T}_{4}}{\left(\mathrm{~T}_{2}-\mathrm{T}_{1}\right)-\left(\mathrm{T}_{3}-\mathrm{T}_{4}\right)}$
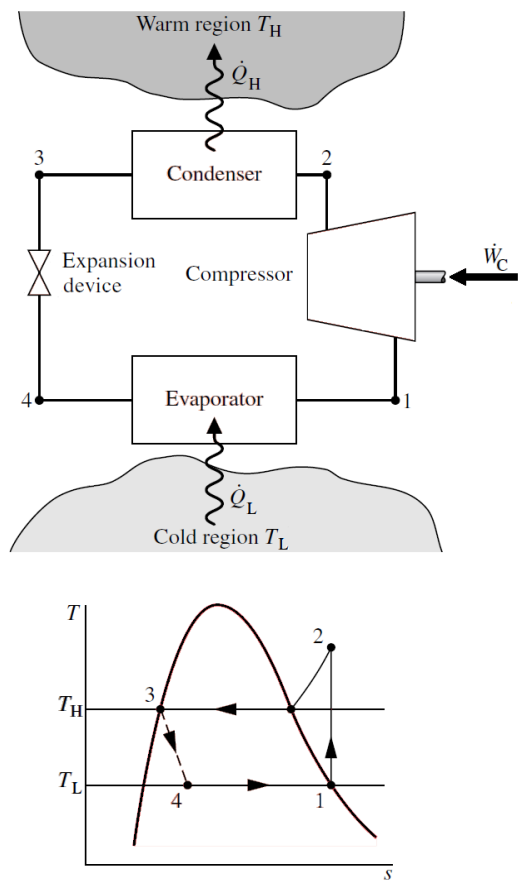

Figure 2. Vapor compression refrigeration cycle (Moran \& Shapiro, 2004).
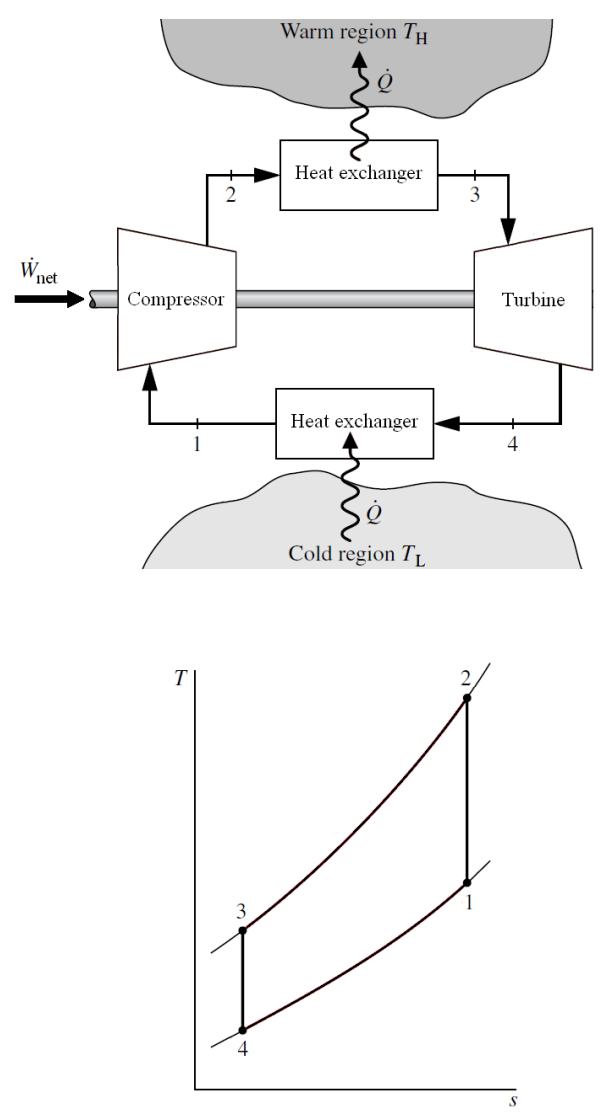

Figure 3. Reverse Brayton closed refrigeration cycle (Moran \& Shapiro, 2004) 


\section{COOLING LOAD DEMAND EVALUATION}

In order to evaluate the cooling load demand for automotive air conditioning systems, the parameters listed in Table 1 were assumed. From such values, peak cooling load demand can be evaluated by Eq. (4):

$$
\dot{\mathrm{Q}}_{\mathrm{L}}=\dot{\mathrm{m}}_{\mathrm{a}}\left[\mathrm{h}_{\mathrm{E}}-\mathrm{h}_{0}-\left(\omega_{\mathrm{E}}-\omega_{0}\right) \mathrm{h}_{\mathrm{w}}\right]
$$

Air enthalpies and absolute humidities of Eq. (4) can be evaluated from Table 1 values and psychometric charts, and condensate enthalpy $h_{w}$ can be obtained from vapor tables. Values for the present case are listed in Table 2. Considering such values, cooling load demand is:

$\dot{\mathrm{Q}}_{\mathrm{L}}=5,68 \mathrm{~kW}=1,6 \mathrm{TR}$

Table 1. Parameters for cooling load demand evaluation (Forrest \& Bhatti, 2002)

\begin{tabular}{cc}
\hline Parameter & Value \\
\hline $\mathrm{T}_{0}$ & $38^{\circ} \mathrm{C}$ \\
$\phi_{0}$ & $40 \%$ \\
$\mathrm{p}_{0}$ & $101,325 \mathrm{kPa}$ \\
$\mathrm{T}_{\mathrm{E}}$ & $10^{\circ} \mathrm{C}$ \\
$\phi_{\mathrm{E}}$ & $100 \%$ \\
$\dot{\mathrm{m}}_{\mathrm{a}}$ & $0,1285 \mathrm{~kg} / \mathrm{s}$ \\
\hline
\end{tabular}

Table 2. Air and water properties for Equation (4)

\begin{tabular}{cc}
\hline Property & Value \\
\hline $\mathrm{h}_{\mathrm{E}}$ & $81,0 \mathrm{~kJ} / \mathrm{kg}$ \\
$\mathrm{h}_{0}$ & $29,0 \mathrm{~kJ} / \mathrm{kg}$ \\
$\omega_{\mathrm{E}}$ & $0,0078 \mathrm{~kg}$ vapor $/ \mathrm{kg}_{\text {dry air }}$ \\
$\omega_{0}$ & $0,0168 \mathrm{~kg}$ vapor $/ \mathrm{kg}_{\text {dry air }}$ \\
$\mathrm{h}_{\mathrm{w}}$ & $42,0 \mathrm{~kJ} / \mathrm{kg}$ \\
\hline
\end{tabular}

\section{SYSTEM DESIGN AND THERMODYNAMIC ANALYSIS}

As stated before, the intent of this work is to analyze the viability of assembling an alternative turbocompression automotive air conditioning system based on the Brayton cycle using a turbocompression-intercooling system configuration available in the market. Thus, the first step of the development was to select a suitable turbocompressor model for the application. Figure 4 presents the compressor and turbine maps of the selected turbocompressor system.
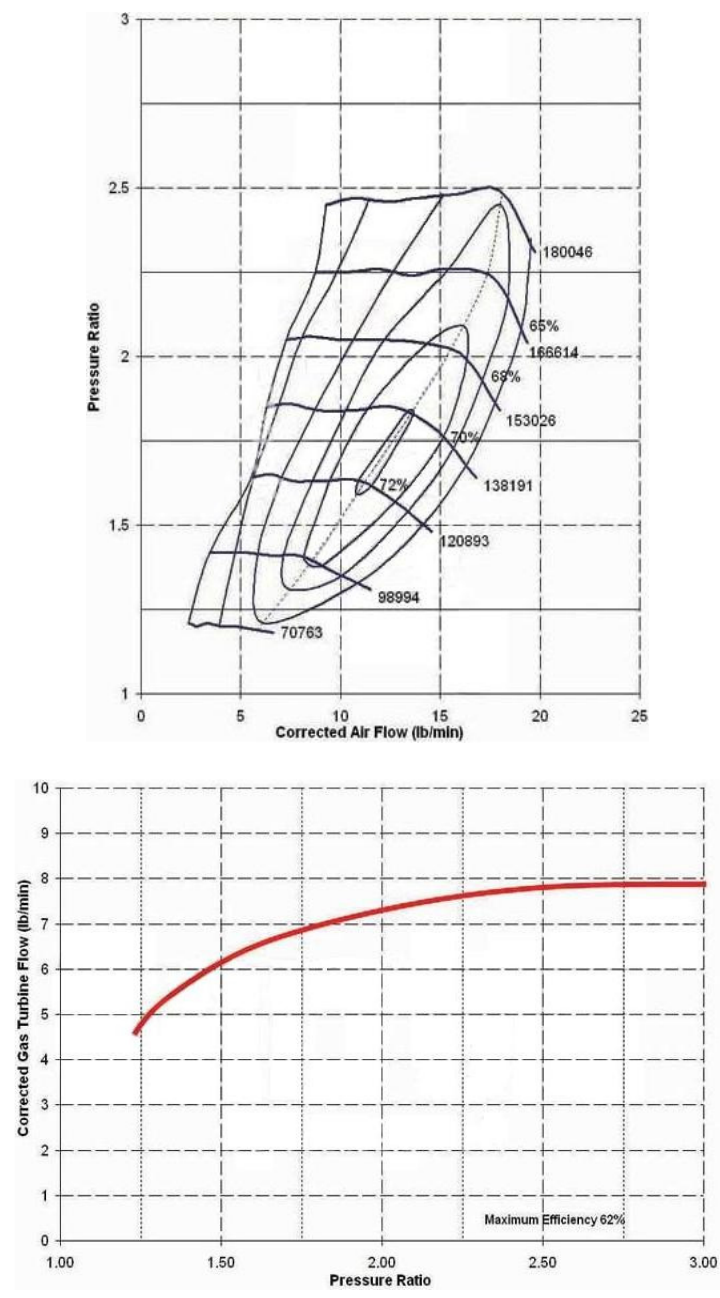

Figure 4. Turbocompressor maps for the selected model (Garrett, 2010)

Assuming a compressor speed of $100.000 \mathrm{rpm}$ and the desired mass flow rate, the turbocompression system operates with a pressure ratio of 1,25 and an isentropic efficiency of about $68 \%$. Considering such values and also assuming air as ideal gas with constant $c_{p}$, it is possible to evaluate air temperature at compressor outlet from isentropic compression:

$\left.\begin{array}{l}\mathrm{T}_{2, \mathrm{~s}} / \mathrm{T}_{1}=\left(\mathrm{p}_{1} / \mathrm{p}_{2}\right)^{[(\mathrm{k}-1) / \mathrm{k}]} \\ \eta_{\mathrm{s}}=\frac{\mathrm{T}_{2, \mathrm{~s}}-\mathrm{T}_{1}}{\mathrm{~T}_{2}-\mathrm{T}_{1}}\end{array}\right\} \Rightarrow \mathrm{T}_{2}=47,6^{\circ} \mathrm{C}$

From the conditions in the vehicle interior and assuming negligible air velocity (worst case scenario), it is possible to evaluate, from Bernoulli equation, that the vehicle interior pressure is equal to $\mathrm{p}_{4}=101,8 \mathrm{kPa}$. Considering the vehicle interior conditions and assuming isenthalpic process in an expansion device, air temperature at the expansion device inlet is: 


$$
\left.\begin{array}{l}
\mathrm{p}_{3}=\mathrm{p}_{2} \\
\mathrm{~h}_{3}=\mathrm{h}_{4}
\end{array}\right\} \Rightarrow \mathrm{T}_{3}=14,7^{\circ} \mathrm{C}
$$

With the air temperatures at compressor outlet and expansion device inlet, the intercooler required capacity is:

$\dot{\mathrm{Q}}_{\text {intercooler }}=\dot{\mathrm{m}}_{\mathrm{a}} \mathrm{c}_{\mathrm{p}, \mathrm{a}}\left(\mathrm{T}_{2}-\mathrm{T}_{3}\right)=4,24 \mathrm{~kW}$

Considering the required intercooling capacity and the available systems in the market, a 2,0 $\mathrm{m}^{2}$ face area air-air intercooler with an auxiliary evaporative cooling system was selected.

\section{$\begin{array}{llll}\text { SYSTEM IMPACT ON } & \text { ENGINE }\end{array}$ PERFORMANCE}

Considering the experimental data provided by the manufacturer, the turbocompressor increases the outlet engine pressure by $3,5 \%$ in the worst case scenario, and the impact on engine power is nearly the same:

$\frac{\dot{\mathrm{W}}_{\text {without turbo }}}{\dot{\mathrm{W}}_{\text {with turbo }}} \approx 1,035$

For a typical small-size car with a maximum engine power of $51 \mathrm{~kW}$, turbocompressor impact on the engine is $1,7 \mathrm{~kW}$, which is similar to the typical compressor power consumption of a conventional air conditioning system (about 1,6-1,7 $\mathrm{kW}$ according to Kaynakli \& Horuz, 2003).

Another aspect to be considered in terms of engine impact is the system weight. The weight of the proposed system was evaluated to be about $11,5 \mathrm{~kg}$, while the conventional system weighs approximately $10,5 \mathrm{~kg}$.

Taking these aspects into account, this first approach indicates that the proposed system would increase fuel consumption, mainly due to higher weight. Nevertheless, considering that system weights are very similar, an optimizing process on proposed system might eliminate such fuel consumption increase.

\section{ENVIRONMENTAL IMPACT}

As stated before, an environmental aspect that affects air conditioning systems is that the halogenated refrigerant typically used in the system contributes to global warming, and the development of a system that eliminates such substances is important.

One of such refrigerants is HFC-134a (tetrafluoroethane), typically used in conventional automotive air conditioning systems. According to the Brazilian automotive manufacturers association (ANFAVEA), about 90 tons of HFC-134a are released into the atmosphere every year due to leakages and system maintenances (. Such amount has a significant environmental impact. So far, the main advantage of the proposed system is connected to this aspect. Considering that it uses air as refrigerant, the turbocompression AC system eliminates this environmental impact.

\section{COST COMPARISON}

In order to evaluate the economic viability of the proposed system, initial and routine maintenance costs were compared for both systems. Initial costs were evaluated by the cost of the main components of both systems, and maintenance costs were considered for a three-year period, which is the typical warranty period for a new vehicle.

Tables 3 and 4 present the comparison results, indicating that the alternative system is about $56 \%$ more expensive than the conventional one; on the other hand, it presents a maintenance cost that is $24 \%$ lower. Nevertheless, considering the three-year warrant period, the savings on maintenance cost are insufficient to pay back the higher initial cost.

\section{CONCLUSION}

A preliminary feasibility analysis of an alternative automotive air conditioning system based on the Brayton cycle was presented, to be assembled using a turbocharging system adapted for this purpose.

Table 3. Initial costs for conventional and proposed AC system

\begin{tabular}{|c|c|}
\hline \multicolumn{2}{|l|}{ Conventional System } \\
\hline Main components & Cost $[R \$]$ \\
\hline Compressor & 800,00 \\
\hline Evaporator / Expansion Device & 500,00 \\
\hline Condenser & 400,00 \\
\hline Total Initial Cost & $1.700,00$ \\
\hline \multicolumn{2}{|l|}{ Proposed System } \\
\hline Main components & Cost $[\mathrm{R} \$]$ \\
\hline Turbocompressor & $2.000,00$ \\
\hline Intercooler & 300,00 \\
\hline Evaporative System & 200,00 \\
\hline Expansion Device & 150,00 \\
\hline Total Initial Cost & $2.650,00$ \\
\hline
\end{tabular}


Table 4. Maintenance costs for conventional and proposed AC system

\begin{tabular}{lc|}
\hline \multicolumn{2}{c}{ Conventional System } \\
\hline \multicolumn{1}{c}{ Maintenance routine } & Cost $[\mathrm{R} \$]$ \\
\hline Refrigerant charge & 100,00 \\
System sanitation & 200,00 \\
Air filter replacement & 180,00 \\
\hline Total Maintenance Cost & 480,00 \\
\hline \multicolumn{2}{c}{ Proposed System } \\
\hline \multicolumn{2}{c}{ Maintenance routine } \\
\hline System sanitation & Cost $[\mathrm{R} \$]$ \\
Air filter replacement & 200,00 \\
\hline Total Maintenance Cost & 480,00 \\
\hline
\end{tabular}

The first part of this study was the thermodynamic analysis of the system, from which a suitable turbocompressor system and an air-air intercooler with auxiliary evaporative cooling subsystem were selected. The next step was an evaluation of the impact of the proposed system on vehicles engine fuel consumption, which indicated that the proposed system has a power requirement similar to that of the conventional system.

Concerning system weight, the analysis indicated that the proposed system is about $1,0 \mathrm{~kg}$ heavier than the conventional system. This is a negative aspect of the proposed system, since it indicates higher fuel consumption. Nevertheless, considering that system weights are very similar, an optimizing process in the proposed system might eliminate such fuel consumption increase.

The main advantage of the proposed system is the elimination of the environmental impact caused by the contribution of halogenated refrigerants to global warming.

In terms of costs, the proposed system presents a 56\% higher initial cost, but on the other hand it has a maintenance cost that is $24 \%$ lower. Nevertheless, considering a three-year warrant period, the savings on maintenance cost do not manage to pay back the higher initial cost.

Considering the results of the preliminary analysis, the proposed system is technically feasible for application in automotive air conditioning, but requires a design optimization process in order to reduce its weight and initial costs, which might allow lower maintenance costs to pay back the alternative system.

As a subsequent study, the suggestion is that new turbo compressors are addressed, which are not available in the domestic market, in search of better compression ratios at levels of lower rotation and lower weight system, which would result in a reduction in vehicle fuel consumption, thus allowing the use of the proposed system.

\section{REFERENCES}

Forrest, W., and Bhatti, M., 2002, Energy efficient automotive air conditioning system, Proceedings of the SAE 2002 World Congress, Detroit, USA.

Kaynakli, Ö., Horuz, I., 2003, An experimental analysis of Automotive Air Conditioning System, International Communications in Heat and Mass Transfer, Vol. 30, No. 2, pp. 273-284.

Moran, M., Shapiro, H., 2004, Fundamentals of Engineering Thermodynamics, $5^{\text {th }}$. Ed., John Wiley \& Sons, Hoboken, USA, 874p.

Garret, 2010, Garrett ${ }^{\circledR}$ Product Catalog, $<$ http://www.turbobygarrett.com/turbobygarrett/catel og/Turbochargers/GT15/GT1548_466755_3.htm>.

Received: June 07, 2009

Revised: July 07, 2009

Accepted: August 07, 2009 